\title{
Experimental Investigations on Mode II Fracture of Concrete with Crushed Granite Stone Fine Aggregate Replacing Sand
}

\author{
Kanchi Balaji Rao ${ }^{\text {a*, Vijaya Bhaskar Desai }{ }^{\mathrm{b}} \text {, D. Jagan Mohan }}{ }^{\mathrm{b}}$ \\ ${ }^{a}$ Structural Engineering Research Centre - CSIR, CSIR Campus, 600 113, Taramani, Chennai, India \\ ${ }^{b}$ Department of Civil Engineeirng, JNTU College of Engineering, 515 002, Anantapur, India
}

Received: March 6, 2011; Revised: October 18, 2011

\begin{abstract}
With a view to implement sustainability concepts (namely, use of locally available materials and industrial by-products) in the concrete construction industry, the possibility of use of crushed stone fine aggregate as replacement to river sand is explored in this paper. Towards this, tests have been carried out on concrete cubes and concrete cylinders. The effect of variation in percentage replacement of river sand with crushed stone fine aggregate on the mechanical properties is studied. In order to popularize the locally available material for the construction of shear critical concrete structures (viz. flat slabs, foundation of heavy structures), the Mode - II fracture behavior of the considered concrete is studied using DCN (Double Central Notched) specimens with different notch to depth, (a/w), ratios of $0.3,0.4,0.5$ and 0.6 . For each $(\mathrm{a} / \mathrm{w})$ ratio five different percentage replacements (viz. 0, 25, 50,75 and 100\%) are considered. The study indicates that both cube compressive strength and split tensile strength increases with the increase in percentage replacement up to $50 \%$ and then gradually decreases. A similar observation was made with respect to the Mode - II fracture energy also. It is noted that the strengths of concrete even with $100 \%$ replacement are higher than the concrete with $0 \%$ replacement suggesting that the locally available crushed stone fine aggregate can be considered as an alternative to the river sand.
\end{abstract}

Keywords: cushed stone fine aggregate, DCN (Double Central Notched) specimen, notch to depth ratio, Mode - II fracture energy

\section{Introduction}

Concrete is one of the most important construction materials. The main ingredients of concrete are cement, fine aggregate (generally river sand), coarse aggregate and water. It is known that while cement production leads to $\mathrm{CO}_{2}$ emission, the green house gas, there is a severe demand on construction sector to reduce these gases and to maintain sustainability of materials. As pointed out by Glavind and Petersen ${ }^{1}$ there is a need to study the mechanical and durability properties of green concrete produced to reduce the environmental impact. According to them one of the ways to produce green concrete is by using inorganic residual products from concrete and other industries. Stone dust is a residual part (inorganic) obtained from crushing of the aggregates. It is an inert material with a particle size between that of cement and sand particles. River sand, which is a fine aggregate in concrete, is becoming a scare material since extensive quarrying is leading to depletion of ground water table and ultimately resulting in an increase in hardness of ground water. There are some regions in India, such as Rayala seema, wherein the average annual rain fall is about $500 \mathrm{~mm} / \mathrm{year}$. In this region, it is very difficult to get good quality natural river sand. The sand obtained from open quarries contain salts and impurities and when used in the construction of reinforced concrete

* e-mail: balajiserc@gmail.com structures will cause surface efflorescence and corrosion of the reinforcement. This in turn would not only reduce the service life of the structures but also adversely affect the aim of achieving sustainability. Within Rayalaseema, the area where from the authors come (i.e. Anantapur), there is abundant granite stone formations. The granite stone crushing industry is famous. During crushing of granite metal, some of the material will get crushed to the size of natural fine aggregate (i.e., less than $4.75 \mathrm{~mm}$ ), which is being treated as a waste by-product in stone crushing industry. However, due to its inertness and angular surfaces the crushed stone fine aggregate provides more specific area imparting better bonding characteristics and thus can act as good fine aggregate in concrete industry (replacing the natural river sand). Hence, the crushed stone fine aggregate, a by-product from local granite stone crushing industry, is considered in this paper as an alternative material for river sand in concrete. This helps in making the construction sector sustainable and also helps in economizing the cost of construction.

One of the aims of this paper is to study the compressive and split tensile strength properties of the crushed stone fine aggregate concrete. In certain design situations, such as flat slabs, concrete foundations carrying heavy loads, containment structure, large magnitude loads have to be 
transferred. In such situations shear carrying capacity of concrete is an important design parameter. With a view to use crushed granite stone fine aggregate (as a partial/complete replacement of the river sand) in the construction of such structures, this paper also examines the Mode - II fracture behavior of concrete. A brief review of the literature related to the studies dealing with characterizing the mechanical properties of concrete with crushed stone as fine aggregate is presented next.

Realizing the importance of the use of crushed stone aggregate as replacement for natural river sand, number of experimental investigations have been reported in the literature. Celik and Marar ${ }^{2}$ considered the crushed stone dust passing through 75 micron BS sieve as partial replacement of sand. By varying the percentage of crushed dust replacing the sand, they concluded that $10 \%$ replacement gives optimal compressive strength. The increase in compressive strength was due to that the dust acts as filler and helps to reduce the total voids content in concrete. However, as the dust content increases more than $10 \%$ the amount of fines in the concrete increases, so much that there is not enough cement paste to coat all the coarse and fine aggregate particles which leads to decrease in compressive strength. Topcu and Ugurlu ${ }^{3}$ also made similar observations. Donza et al. ${ }^{4}$ noted that crushed granite sand concrete have better performance than natural sand concrete because for equal mortar compressive strength, the concrete with crushed granite sand has higher compressive strength than concrete with natural river sand. The shape and texture of crushed granite sand particles have an important effect on the interlocking of paste and aggregate particles. They also explored the effect of replacement of natural river sand with three types of mineral aggregates. They found that all mixtures of concrete with granite, limestone and dolomite as crushed fine aggregate, displayed considerable workability loss after 20 minutes. To achieve required workability they used super plasticizer. From the experimental investigations they concluded that, concrete with granite crushed sand has higher compressive strength, at all ages, than concrete with river sand. The increase in compressive strength was related to strong paste-fine aggregate interface and the intrinsic strength of granite particles. Flexural strength of granite crushed sand mix showed higher strength values than concrete with river sand mix at equivalent test ages. The improvement of the paste-fine aggregate transition zone was attributed to the rough texture of granite crushed sand, which increases the mechanical interlocking with cement paste. Concrete with granite crushed sand showed lower split tensile strength at 28 days and $14 \%$ higher value than concrete with river sand at one year. Modulus of elasticity of river sand concrete was always higher than concrete with granite crushed sand.

Ribero et al. ${ }^{5}$ compared the Mode - I fracture energy of mortar and concrete produced with crushed rock and pebble aggregates using $0,10,20,30$ and $40 \%$ of aggregates mixed with standard mortar and applying wedge splitting test for stable crack growth. The concrete with crushed rock show higher crack growth resistance than those with pebbles.

Zhu and Tang ${ }^{6}$ have carried out a numerical simulation study on shear fracture process of concrete, using mesoscopic mechanical model, in double edge notched (DEN)- and double central notched (DCN)- specimens loaded in shear. In the simulation they assumed the concrete as a three phase composite material consisting of matrices, aggregates and matrix-aggregate interfaces. They applied an elastic finite element analysis program as the basic stress analysis tool while the elastic damage mechanics is used to describe the constitutive law of meso-level element. They considered maximum tensile strain criterion and Mohr-coulomb criterion as damage thresholds and obtained heterogeneous stress field distribution of concrete from numerical simulation. The crack propagation process simulated with this model showed good agreement with the experimental observations. From their simulation they identified that the two pre-existing notches in the shear specimens (DEN and DCN) do not propagate the crack simultaneously because of the heterogeneous material properties of concrete. Also in case of DCN specimen, the crack propagation was generally confined to the plane along the direction of pre-existing crack. The crack propagation and final fracture in both DEN and DCN specimens of concrete are predominantly caused by tensile damage at the mesoscopic level due to heterogeneous material properties of concrete and shear fracture is observed at macroscopic level.

Recently, Lavato et al. ${ }^{7}$ using response surface methodology, evaluated the mechanical (compressive strength, tensile strength and elastic modulus) and durability properties (water absorption and carbonation depth) of concretes produced with different percentage replacements of the natural aggregates with recycled coarse- and fineaggregates produced from the construction and demolition waste, with different water cement ratios. Their results showed decrease in the compressive strength, tensile strength, elastic modulus, increase in water absorption and increase in the carbonation depth with percentage replacement. They also evaluated the concrete production costs. From economical and technical point of view they suggested that, concretes with $50 \%$ substitution of natural aggregates by recycled aggregates, may achieve compressive strengths up to $25 \mathrm{MPa}$, with carbonation depths similar to that of the reference concrete, as long as the water cement ratio is less than 0.60 . This study clearly brings out the need to conduct carefully planned experimental investigations to determine the optimal use of wastes to achieve sustainability in concrete production. It may be noted that experimental studies similar to the one reported by Lavato et al. ${ }^{7}$, are required to determine use of optimal quantity of locally available material to achieve sustainability in concrete construction.

From the brief review of literature presented above it is noted that the crushed stone fine aggregate and stone dust can be advantageously used as replacement of natural river sand in optimal quantity depending on grading of the aggregate. While the above studies have focused on examining the suitability of crushed stone fine aggregate and dust in improving the mechanical properties of concrete such as compressive strength, flexural strength, split tensile strength, modulus of elasticity, investigations related to Mode - II fracture behavior of crushed stone fine aggregate concrete has not been come across. The main aim of this paper is to present the details of experimental investigations carried out on compressive strength, split tensile strength and Mode - II fracture behavior of concrete using DCN (Double Central Notched) specimens ${ }^{8}$, (Figure 1) containing different 


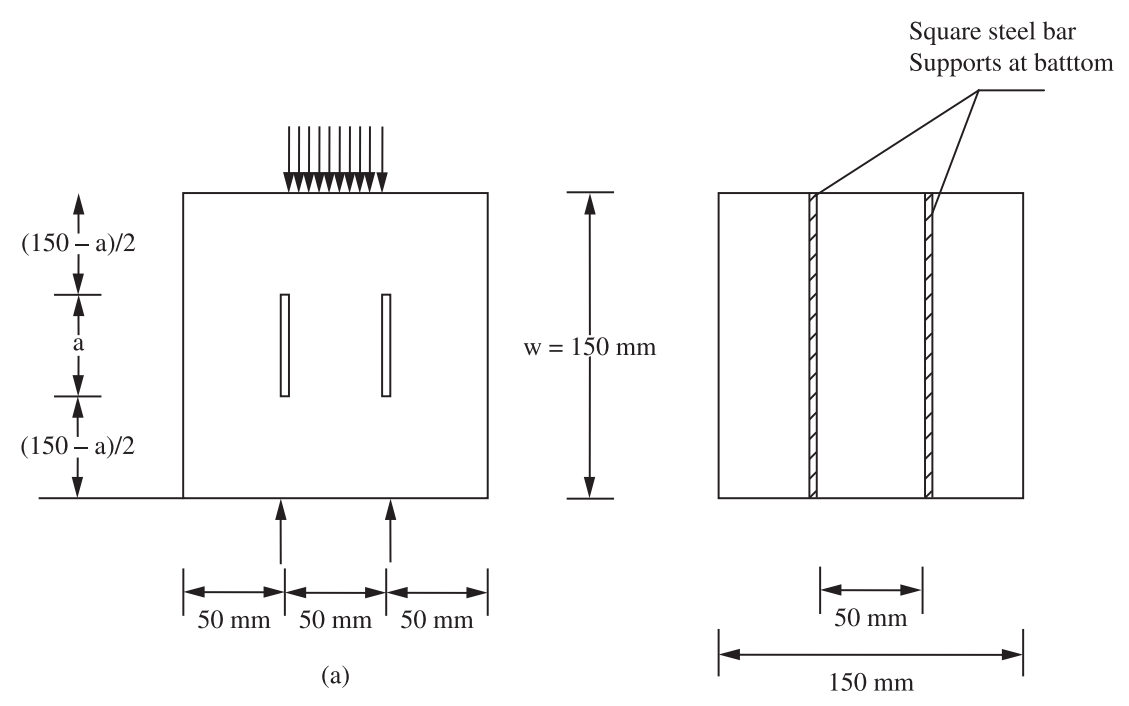

(b)

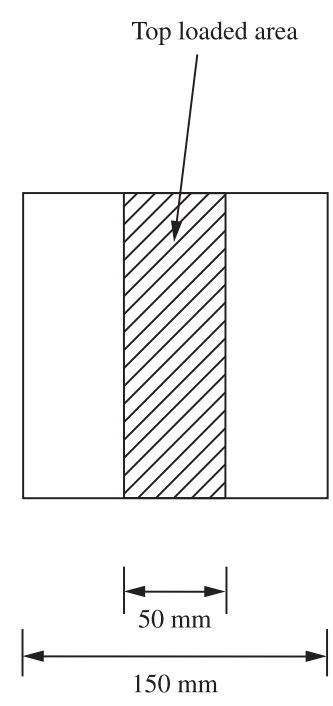

(c)

Figure 1. Geometrical details of DCN (Double Central Notched) specimen. a) Loading and support arrangement in elevation while testing, b) bottom view while testing, and c) top view while testing.

combinations of crushed stone fine aggregate and natural river sand. The locally available crushed stone fine aggregate is used in this study to explore and demonstrate the use of sustainable materials in concrete construction. The DCN specimen is a concrete specimen having a cubical shape with two axi-symmetrically placed notches of width $2 \mathrm{~mm}$ with varying length and running through the thickness of the specimen. More details of DCN specimen, including the type of applied loading are shown in Figure 1 and in Desayi et al. ${ }^{8}$.

\section{Experimental Work}

\subsection{Materials used}

The materials used in the experimental programme (Figure 2) are ordinary Portland cement of 53 grade (I.S:12269-1987 ${ }^{\circ}$ ) having specific gravity of 3.2 with initial setting time of 35 minutes, final setting time of 500 minutes and with normal consistency of $33.5 \%$. Locally available river sand has been used as a fine aggregate, which is free from clay, silt and organic impurities and passing through $4.75 \mathrm{~mm}$ size I.S sieve. Its specific gravity is found to be 2.625. The sieve analysis results of sand confirms to zone -1 . Locally available crushed stone fine aggregate passing through $4.75 \mathrm{~mm}$ sieve from the granite stone crusher plants has been used as a partial/full replacement of natural river sand (i.e. $0,25,50,75$ and 100 percentage by weight of sand). The grading curves of crushed stone fine aggregate and sand are shown in Figure 3. The loose density of crushed stone fine aggregate is $1397 \mathrm{~kg} \cdot \mathrm{m}^{-3}$ as against a value of $1590 \mathrm{~kg} \cdot \mathrm{m}^{-3}$ for river sand. The compact density of crushed stone fine aggregate is $1713 \mathrm{~kg} \cdot \mathrm{m}^{-3}$ while that for river sand is $1700 \mathrm{~kg} . \mathrm{m}^{-3}$. The specific gravity of the crushed stone fine aggregate varies in the range 2.54 to 2.64. The coarse aggregate consists of locally available crushed granite metal passing through $20 \mathrm{~mm}$ sieve. The water used

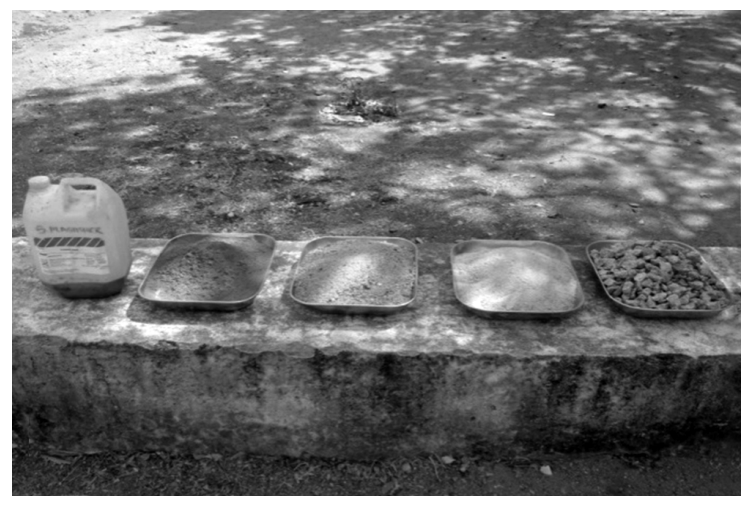

Figure 2. Super plasticizer, cement, sand, crushed stone fine aggregate and coarse aggregate.

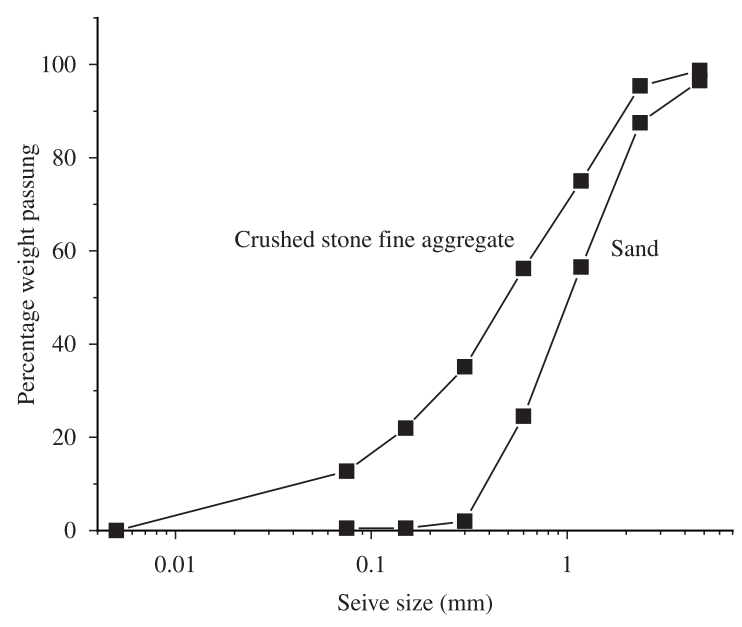

Figure 3. Grading curves of crushed stone fine aggregate and sand. 
in this experimental investigation is locally available potable water. For each percentage replacement of fine aggregate, trials are made to arrive at the optimum dosage of super plasticizer Conplast SP-430 to get a slump of $(100 \pm 10) \mathrm{mm}$, keeping water-cement ratio of 0.5 as constant. This dosage of super plasticizer is then added in casting the specimens of a given batch.

\subsection{Casting the specimens}

The M20 concrete mix has been designed using ISI method (IS:10262-1982 $2^{[10]}$ ). The mix proportion obtained is $1: 1.58: 2.86$ with a water cement ratio of 0.5 . The river sand has been replaced by crushed stone fine aggregate in percentages of $0,25,50,75$ and 100 . For each percentage replacement, 12 cubes of DCN specimens of size of $150 \times 150 \times 150 \mathrm{~mm}$ with notch depth ratios, $(\mathrm{a} / \mathrm{w})$, of 0.3 , $0.4,0.5$ and 0.6 ; three plain (i.e. un-notched) cubes of size $150 \times 150 \times 150 \mathrm{~mm}$ and, three cylinders of size $150 \mathrm{~mm}$ diameter and $300 \mathrm{~mm}$ height are cast. For each combination of parameters considered in this investigation three similar DCN specimens have been cast and tested. Figure 1 shows the geometrical details of the DCN specimen. Notches of $2 \mathrm{~mm}$ thick are introduced at one-third points centrally as shown. The notch depths provided are 45, 60, 75 and $90 \mathrm{~mm}$ running throughout the width of the specimen. The shear resisting areas corresponding to $(\mathrm{a} / \mathrm{w})$ considered are $31500,27000,22500$ and $18000 \mathrm{~mm}^{2}$, respectively. It is noted that the $(\mathrm{a} / \mathrm{w})$ ratios considered satisfy the condition specified by Reinhardt and $\mathrm{Xu}^{11}$ namely, the difference in ligament lengths should be large enough so that the effect of inhomogeneity of concrete can be ignored.

For all test specimens, moulds were kept on the vibrating table and the concrete was poured into the moulds in three layers each layer being compacted thoroughly and uniformly with a tamping rod to avoid honey combing. Finally all specimens were vibrated on the table vibrator after filling up the moulds up to the brim. The vibration was effected for seven seconds and it was maintained constant for all specimens and all the other castings. The steel plates forming notches are removed after three hours of casting carefully and neatly finished. However the specimens were demoulded after twenty four hours of casting and were kept immersed in a clean water tank for curing. After 28 days of curing the specimens were taken out of water and were allowed to dry under shade for few hours.

\subsection{Loading arrangement and testing of the specimens}

All the specimens are white washed and tested in a $2000 \mathrm{kN}$ digital compression testing machine with a uniform rate of loading of $0.1 \mathrm{kN} / \mathrm{sec}$. The loading was controlled through the lever arrangement fitted to the hydraulic machine. The applied loading is monitored through the indicator. If the rate of loading exceeds the set loading rate, a red LED glows on the panel board, on the other hand, if the actual loading is less than set loading rate then a yellow LED glows on the panel board.

Cubes are tested for the crushing strength, cylinders are tested for the split tensile strength and DCN specimens are tested for characterizing the in-plane shear behavior. It is to be noted that, though the loading was applied continuously during testing of the DCN specimens, the displacements, if any, are noted at regular loading increments (of $10 \mathrm{kN}$ ), and, the initiation and propagation of cracks are observed continuously, such that the load-displacement curves are obtained.

The loading arrangement for testing of DCN specimens is shown in Figure 4. For measuring the in-plane shear displacement of the central one third portion of the DCN specimen four LVDTs (of least count $0.01 \mathrm{~mm}$ ) are arranged as shown in Figure 4. The LVDTs have been arranged such that they represent the localized in-plane shear displacements, thereby avoiding noise (Reinhardt and $\left.\mathrm{Xu}^{11}\right)$. To prevent horizontal cracking vertical steel clamps are fixed to the outer ends of the DCN specimen. The LVDT readings are taken at load increments of $10 \mathrm{kN}$. Then, the average of four LVDT readings is taken to represent the shear displacement at a given stage of loading. Also, the loads corresponding to the first crack load $\left(\mathrm{P}_{\text {cr }}\right)$ and the ultimate load $\left(\mathrm{P}_{\mathrm{u}}\right)$ are noted.

During the experimentation, while in most cases the crack initiation was visually observed at the top edge of one or both the notches and then the cracks formed at the bottom edge of the one or both the notches; in some cases visual crack initiation (first) occurred at the bottom edge of the notch(es) and then at the top of the notch(es). Final crack patterns are shown in Figure 5. It can be observed from Figure 5 that there exists a deviation from verticality of the crack path (i.e the crack propagates in an inclined direction from the tip of the notch). The variation of compressiveand split tensile-strengths of concrete with percentage replacement is shown in Figures 6 and 7, respectively. The variation of the load corresponding to the appearance of first visual crack (i.e. first crack load) and the corresponding strength (computed based on the shear resisting ligament area) with percentage replacement, for different ( $\mathrm{a} / \mathrm{w})$, are shown in Figures 8 and 9, respectively.

\subsection{Load vs. inplane shear displacement behavior}

An attempt has been made in this investigation to study the variations in Mode II fracture energy of concrete with varying percentages of replacement of natural sand with crushed stone fine aggregate. In order to carry out this study, experimentally determined load-displacement curves are used. As already indicated, for a given combination of $(\mathrm{a} / \mathrm{w})$ ratio and percentage replacement, there are three nominally similar specimens. At every $10 \mathrm{kN}$ load increment, the mean value of displacement of the three specimens is computed. Also the average $\mathrm{P}_{c r}$ and $\mathrm{P}_{u}$ (of three nominally similar specimens) are used for drawing the load displacement curve. Thus, for a given combination of parameters considered (for a given notch depth ratio and percentage replacement of fine aggregate) one load-displacement curve is obtained.

The load-displacement curve (with all details) is shown in Figure 10, typically for $(\mathrm{a} / \mathrm{w})=0.3$ and percentage replacement of 25. The load-displacement curves for all the DCN specimens considered in this study are shown in Figure 11. 


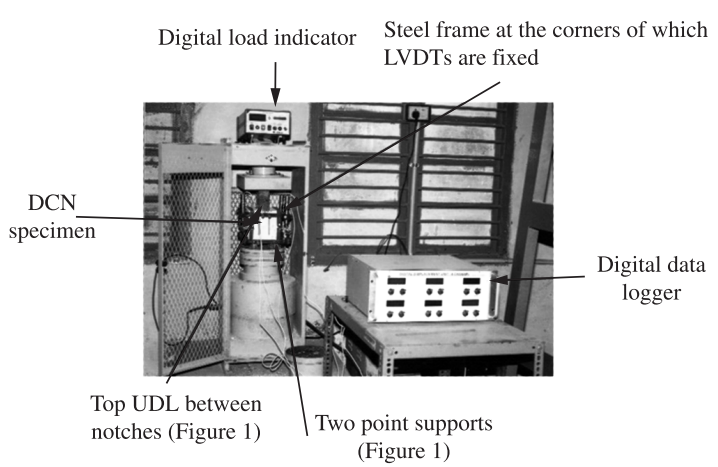

Figure 4. Test setup for DCN specimen.

\subsection{Determination of fracture energy}

The area under the load-displacement curve divided by the shear resisting area gives the fracture energy in Mode II $\left(\mathrm{G}_{\mathrm{IIF}}\right)$. It is noted that, since the present set of experiments have been conducted in load-controlled testing machine, the dropping portion of the load-displacement curve could not be obtained. In the present study, since the fracture tests have been conducted under load controlled conditions, the computed value of the fracture energy may be construed as work of fracture (Reinhadt and $\mathrm{Xu}^{11}$ ) or specific energy release $\left(\mathrm{Ferro}^{12}\right)$. Thus, in the present investigation, the Mode II fracture energy is obtained by evaluating the area under the load-displacement curve (shown as darkened portion in

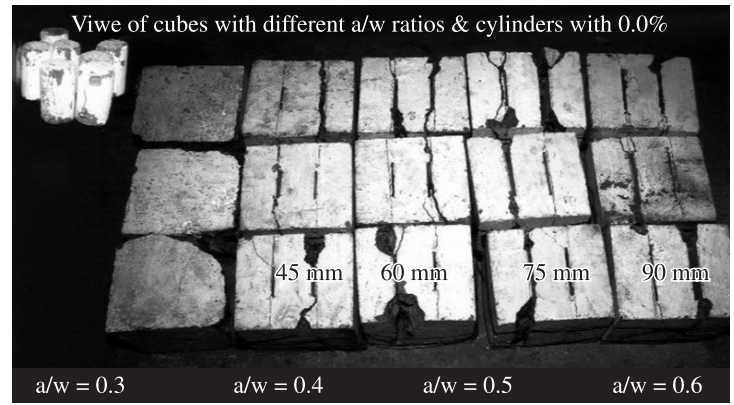

Cubes DCN - a/w $=0.3 D C N-a / w=0.4 D C N-a / w=0.5 D C N-a / w=0.6$

Crack patterns after testing with $0 \%$ replacement of natural sand with crushed stone fine aggregate

(a)

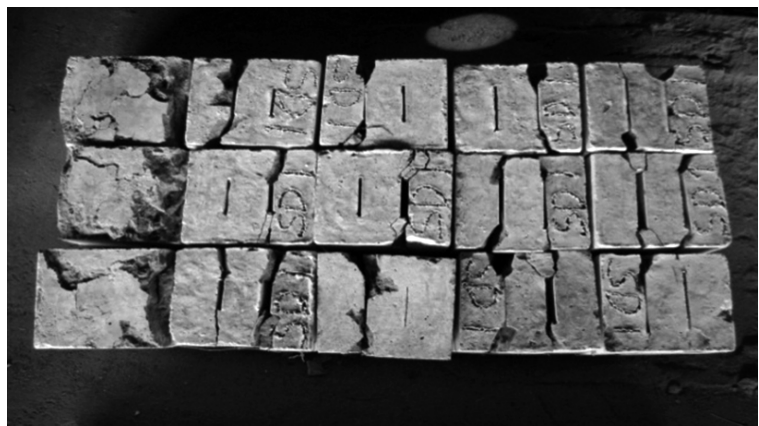

Cubes $\mathrm{DCN}-\mathrm{a} / \mathrm{w}=0.3 \mathrm{DCN}-\mathrm{a} / \mathrm{w}=0.4 \mathrm{DCN}-\mathrm{a} / \mathrm{w}=0.5 \mathrm{DCN}-\mathrm{a} / \mathrm{w}$
Crack patterns after testing with $25 \%$ replacement of natural sand with crushed stone fine aggregate

(b)

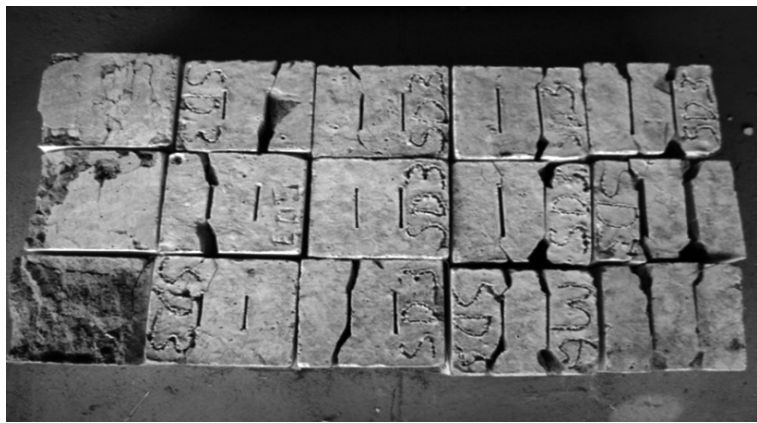

Cubes $\mathrm{DCN}-\mathrm{a} / \mathrm{w}=0.3 \mathrm{DCN}-\mathrm{a} / \mathrm{w}=0.4 \mathrm{DCN}-\mathrm{a} / \mathrm{w}=0.5 \mathrm{DCN}-\mathrm{a} / \mathrm{w}$
Crack patterns after testing with $75 \%$ replacement of natural sand with crushed stone fine aggregate

(d)

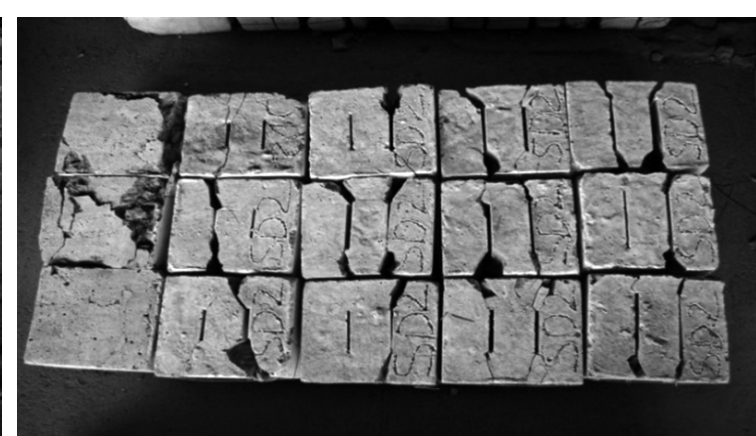

$D C N-a / w=0.3 D C N-a / w=0.4 D C N-a / w=0.5 D C N-a / w=0.6$ Crack patterns after testing with $50 \%$ replacement of natural sand with crushed stone fine aggregate

(c)

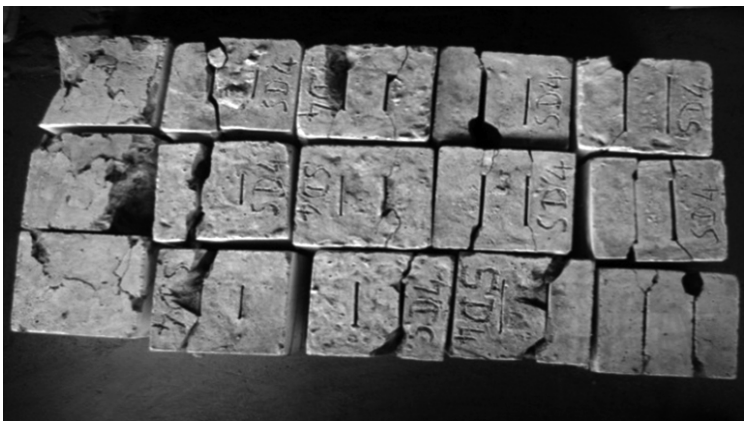

$D C N-a / w=0.3 D C N-a / w=0.4 D C N-a / w=0.5 D C N-a / w=0.6$ Crack patterns after testing with $100 \%$ replacement of natural sand with crushed stone fine aggregate

(e)

Figure 5. Final crack patterns of the DCN specimens. 


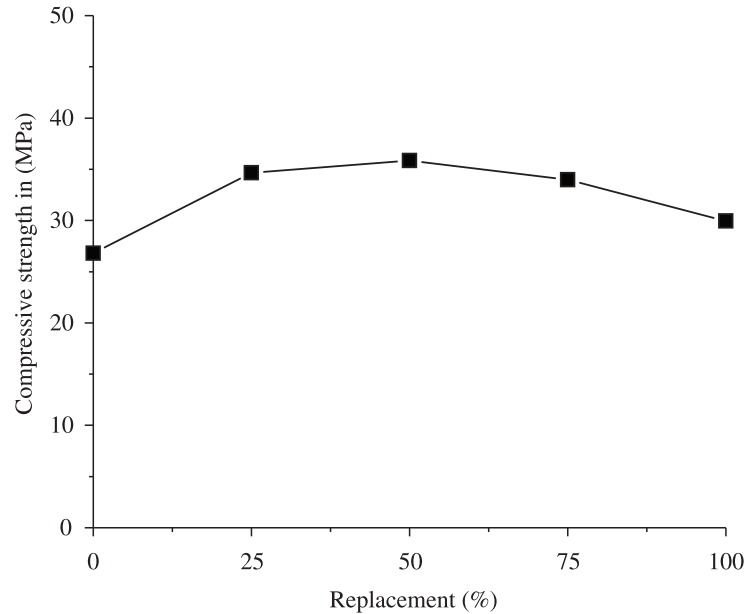

Figure 6. Variation of ultimate compressive strength of concrete with percentage replacement of river sand (with crushed stone fine aggregate).

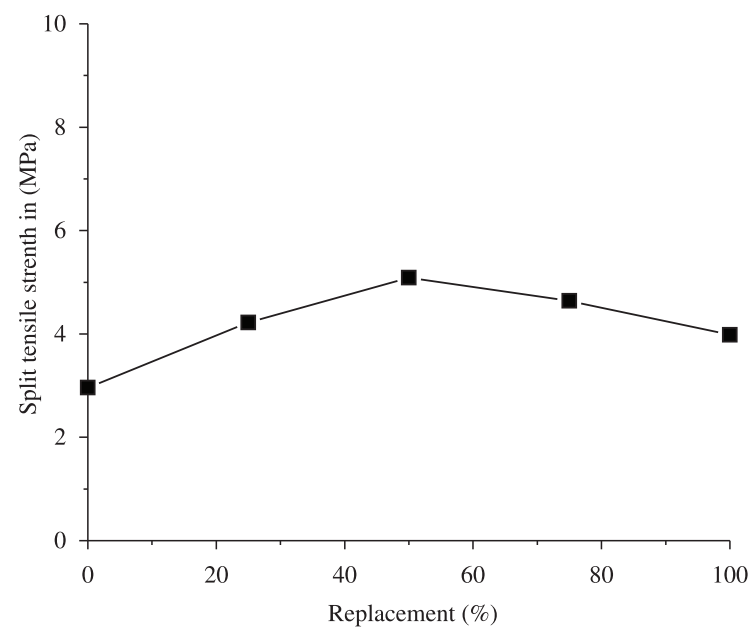

Figure 7. Variation of split tensile strength of concrete with percentage replacement of river sand (with crushed stone fine aggregate).

Figure 10) and divided by the corresponding shear resisting area (cross section area of ligaments). A best-fit equation is fitted to the experimentally obtained load-displacement curve. The area under this curve is computed using ORIGIN software. A plot of the fracture energy versus the percentage replacement is made, for various $(\mathrm{a} / \mathrm{w})$ ratios considered, and the same is shown in Figure 12.

\section{Discussion of Results}

\subsection{Variations in compressive strength, split tensile strength and first crack strength}

For a given set of specimens, average values of compressive strength of cubes and split tensile strength of cylinders are calculated. The results of compressive strength and split tensile strengths of concretes considered

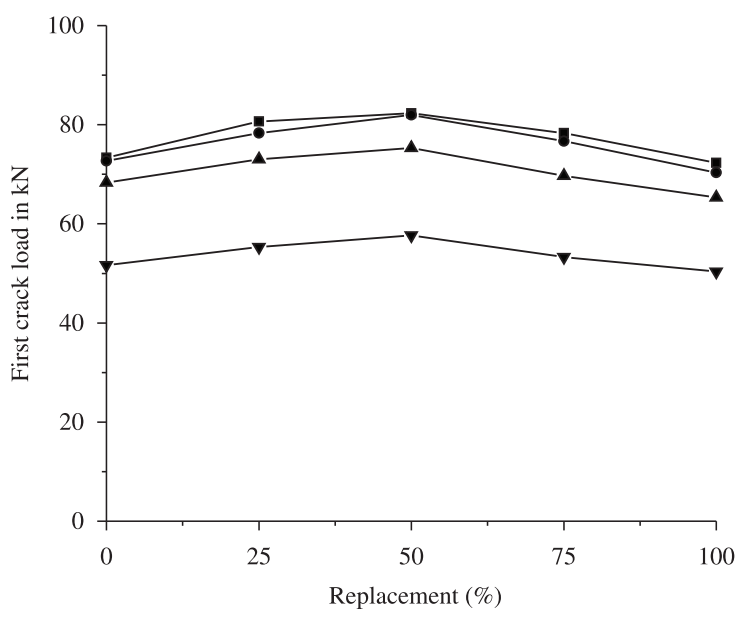

$\rightarrow \mathrm{a} / \mathrm{w}=0.3 \rightarrow \mathrm{a} / \mathrm{w}=0.4 \rightarrow \mathrm{a} / \mathrm{w}=0.5 \rightarrow \mathrm{a} / \mathrm{w}=0.6$

Figure 8. Variation of the load corresponding to appearance of first visual crack with percentage replacement of river sand (with crushed stone fine aggregate) in Mode - II fracture.

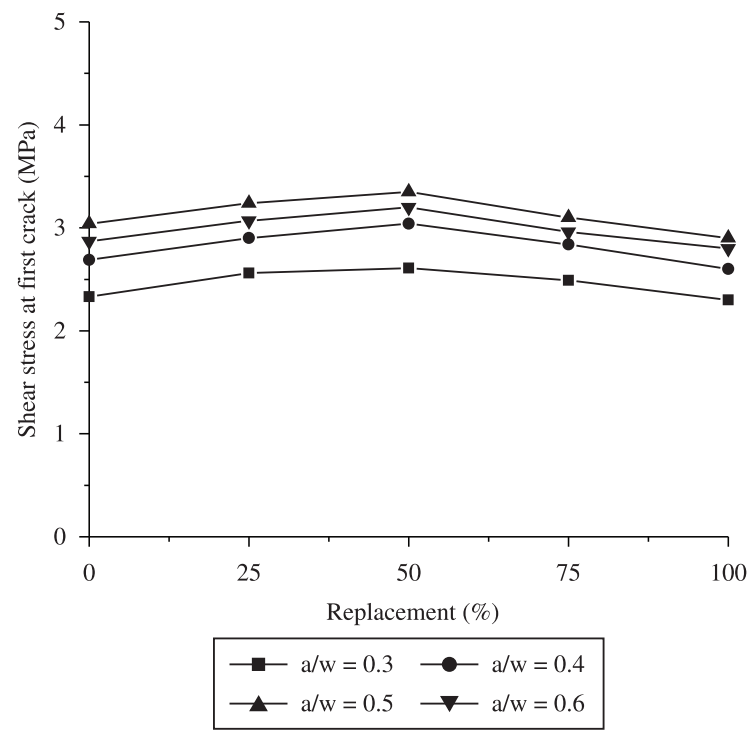

Figure 9. Variation of shear stress corresponding to appearance of first visual crack with percentage replacement of river sand (with crushed stone fine aggregate) in Mode - II fracture.

in this investigation are presented in Figures 6 and 7. From the plot of variation of cube compressive strength $\left(f_{c u}\right)$ with percentage of crushed stone fine aggregate replacing the sand (Figure 6), it is observed that the cube compressive strength attains the maximum value for $50 \%$ replacement. The value of $\mathrm{f}_{\mathrm{cu}}$ even for $100 \%$ replacement is higher than $0 \%$ replacement, suggesting that this material can be used as a replacement for the natural river sand and thus meeting the sustainability goals (Glavind and Petersen ${ }^{1}$ ). A similar observation is made with respect split tensile strength of concrete (Figure 7). As reported by Donza et al. ${ }^{4}$, the increase in the strengths of concrete could be due to strong 


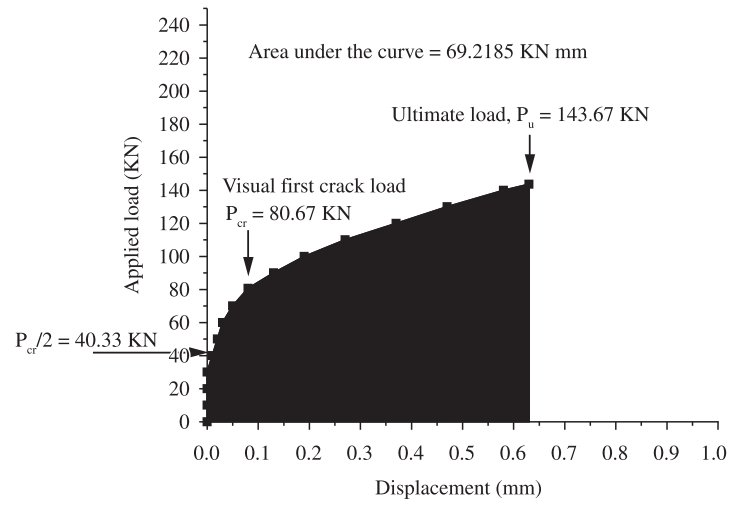

Figure 10. Experimental load vs. load-line displacement curve of DCN specimen with $25 \%$ replacement and with $\mathrm{a} / \mathrm{w}=0.3$.

paste-fine aggregate interface and the intrinsic strength of granite particles.

From Figure 3 it is noted that the crushed stone fine aggregate is well graded than sand and also has $12.75 \%$ finer particles, less than 75 micron size, where as sand is having $0.5 \%$ only. Also the use of crushed stone fine aggregate in concrete would result in better packing due to finer particles and interlocking effect due to angular surfaces. This could perhaps be the reason for realizing higher strengths of concrete even at $100 \%$ replacement (compared to $0 \%$ replacement). However, in this investigation since the water cement ratio is maintained constant at 0.50 , the amount of water available for hydration of cement is same, irrespective of percentage replacement of fine aggregate. As the percentage replacement increases, the amount of fines of crushed stone fine aggregate increases and perhaps would compete with the cement particles in packing. Since the crushed stone fine aggregate particles are not binders they would not involve in hydration and this increases the possibility of formation of weaker transition zones. This could be the reason for decrease in strength of concrete beyond 50\% replacement. It is noted that micro structural studies are required to be conducted to probe this reasoning further.

For DCN specimens, for each $(\mathrm{a} / \mathrm{w})$ ratio and percentage replacement considered, average crack initiation load $\left(\mathrm{P}_{\mathrm{cr}}\right)$, that is first crack load, and ultimate load $\left(\mathrm{P}_{\mathrm{u}}\right)$ are noted. The variation of first visual cracking load with variation in the percentage of crushed stone fine aggregate (replacing sand) is shown in Figure 8. The shear strength corresponding to $\mathrm{P}_{\mathrm{cr}}$ for different combinations of $(\mathrm{a} / \mathrm{w})$ and percentage replacements are shown in Figure 9. In case of DCN specimens, from plots of variation between the applied load corresponding to first crack and the percentage replacement of crushed stone fine aggregate it is observed that the first crack load varies with a/w ratio. For a given a/w ratio, the first crack load is maximum at $50 \%$ replacement. The possible reason for this is as explained in for cube compressive strength and split tensile strengths. For a given percentage replacement, as expected, the first crack load, in general, decreases with the increase in $(\mathrm{a} / \mathrm{w})$ ratio (Figure 8). This is due to decrease in shear resisting area.

\subsection{Crack patterns}

Attempts have been made in the literature to study the fracture of concrete under shear. The experimental observations of van Mier ${ }^{13,14}$ and van Geel $^{15}$ on concrete prisms, for both uniaxial and confined compression, shown that the frictional resistance from the loading system will have effect on the direction of the shear crack orientation. Also, Bazant and Pfieffer ${ }^{16}$ showed that crack band propagates sideways when shear force zone is wide and vertically when the shear force zone is narrow (it is noted that the shear force applied in the present experimental programme is over wider area and hence inclination of cracks). From the experimental final crack patterns it is found that, the cracks ahead of notch tips are more inclined in specimens with lesser $(\mathrm{a} / \mathrm{w})$ than those with higher $(\mathrm{a} / \mathrm{w})$ ratios considered. This observation could be due to inherent inhomogeneity of concrete. In most of the specimens with $(\mathrm{a} / \mathrm{w})$ ratios of 0.3 and 0.4 the failure has occurred due to propagation of crack in the ligaments ahead of the same notch. Thus, formation of a single though slightly jaggered crack has led to failure of these specimens. A possible reason could be provided using the weakest link hypothesis proposed by Bolotin ${ }^{17}$ and Whitmann et al. ${ }^{18}$. That is, it is possible that if interfacial transition zone ahead of a notch tip develops into a weakest link and due to stress concentration the crack will propagate in line with the notch in a ragged fashion. This crack would suppress the formation of a crack ahead of the other notch. And thus, Mode - II fracture would occur in these specimens by formation of cracks along one of the two notches. From Figure 5, it can be observed that for 25,50 and $75 \%$ replacements, for higher values of $(\mathrm{a} / \mathrm{w})$, i.e. 0.5 and 0.6 the failure occurs due to the formation of cracks in the ligaments ahead of both the notches; more or less in the vertical direction. This could be due to the fact that the shear resisting areas are lesser for these specimens compared to the specimens with $(\mathrm{a} / \mathrm{w})=0.3$ and 0.4 and hence all the four ligaments effectively, together, participate in resisting the shear. Thus, the shear resisting ligaments can be construed to be in parallel in offering resistance to the propagation of crack. This behavior is also witnessed through Figure 9, that higher first crack shear strength (i.e. shear stress at first crack) of specimens with higher $(\mathrm{a} / \mathrm{w})$ ratios for all percentage replacements.

This type of shear fracture was also observed by Zhu and Tang $^{6}$ in their numerical simulations on DCN specimens, in which the heterogeneous material properties of concrete caused the heterogeneous stress filed distribution ahead of the notch tips causing shear failure plane along one of the notches having more stress concentration than the other.

\subsection{Load and load-line displacement behavior}

From load-displacement curves shown in Figure 11 it is observed that the specimens show high rigidity and hence the load-line displacements are small. Noting that the least count of LVDT is $0.01 \mathrm{~mm}$, the minimum average deformation that could be measured is $0.01 \mathrm{~mm}$. From Figure 10, it may be noted that at $\left(\mathrm{P}_{\mathrm{cr}} / 2\right)$ itself there is a change in stiffness suggesting that the internal microcracks would have started coalescing ahead of notches resulting in a crack. A similar observation was reported in Reinhardt and $\mathrm{Xu}^{11}$ and by $\mathrm{Sih}^{19}$ 
(i.e. the micro-cracking starts at a load approximately equal to $50 \%$ of first visual cracking load). These observations along with the numerical simulation results presented by Zhu and Tang ${ }^{6}$ suggest that the deformation up to the load $\left(\mathrm{P}_{\mathrm{cr}} / 2\right)$ occurs due to shear fracture. However, it is noted that determination of the state of stress of an element near the vicinity of crack can be quite complex ${ }^{12,14}$. Since the interest in the experimental investigation has been on average stress strain behavior of concrete ahead of crack tip, 2D pure shear condition is assumed to estimate the shearing strain. It is noted that the load-line displacements are measured, using the LVDTs, over a gauge length of $100 \mathrm{~mm}$.

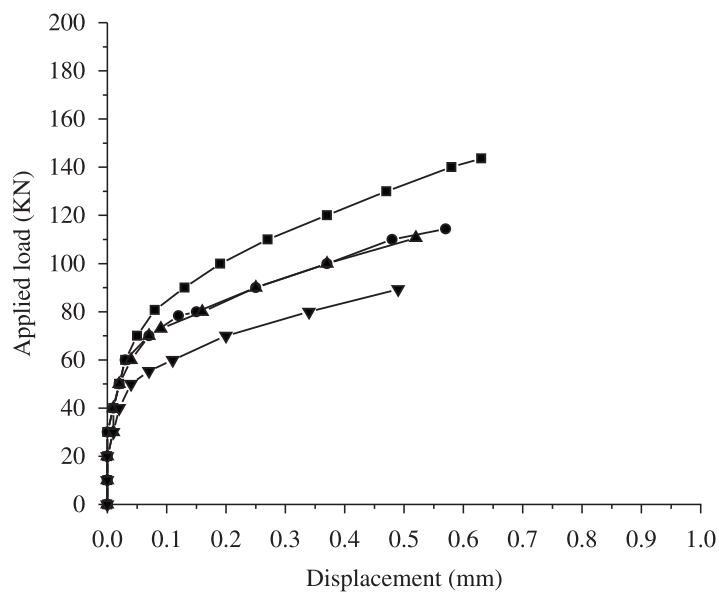

(a)
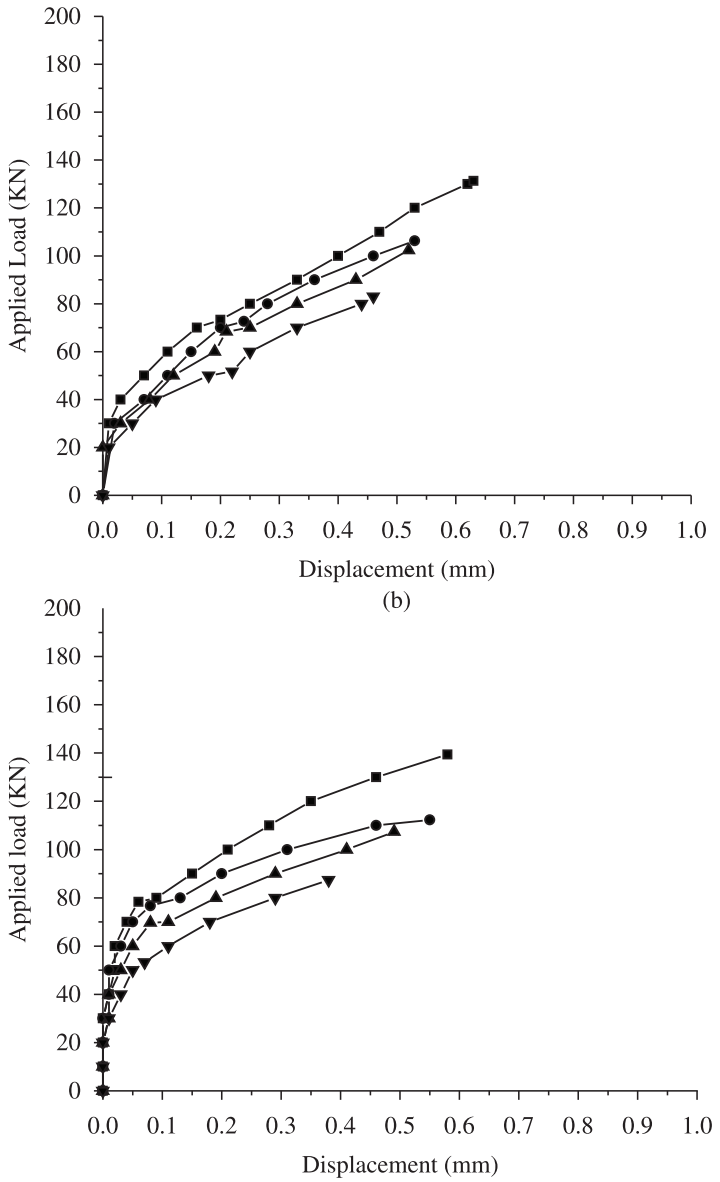

(d)

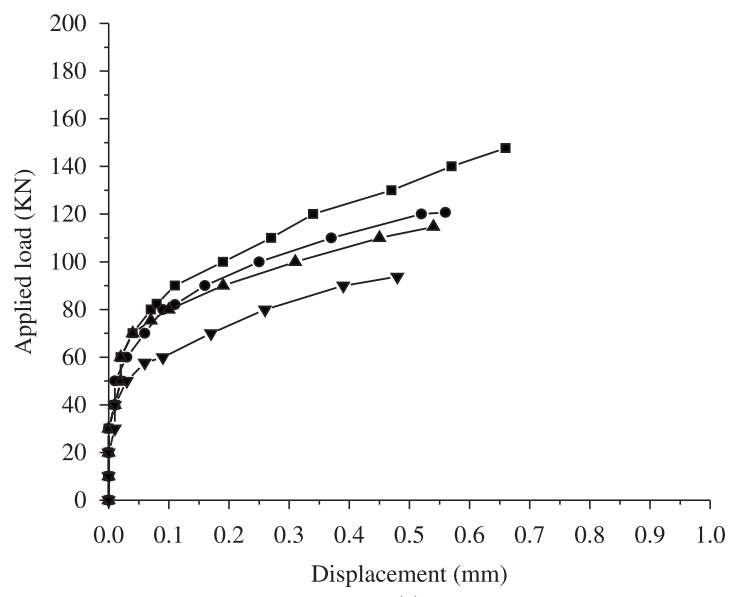

(c)

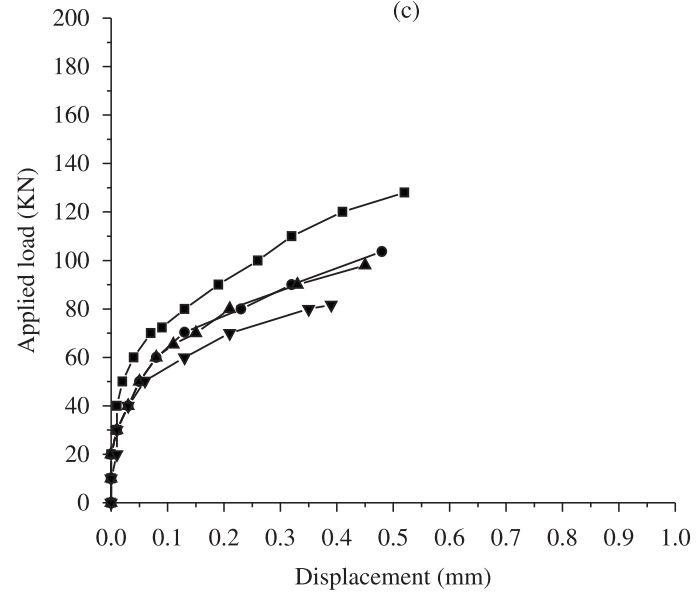

(e)

$$
\rightarrow \mathrm{a} / \mathrm{w}=0.3 \rightarrow \mathrm{a} / \mathrm{w}=0.4 \rightarrow \mathrm{a} / \mathrm{w}=0.5 \rightarrow \mathrm{a} / \mathrm{w}=0.6
$$

Figure 11. Experimental load vs. load-line displacement curves of all the DCN specimens tested (each curve is the average of three nominally similar specimens). 


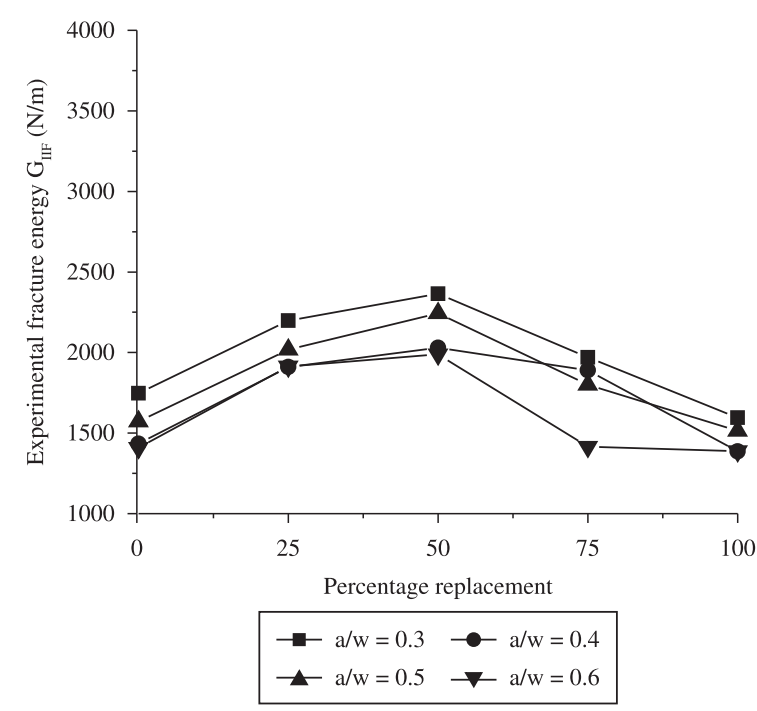

Figure 12. Variation between experimental fracture energy, $\mathrm{G}_{\mathrm{IIF}}$, with percentage replacement of river sand (with crushed stone fine aggregate).

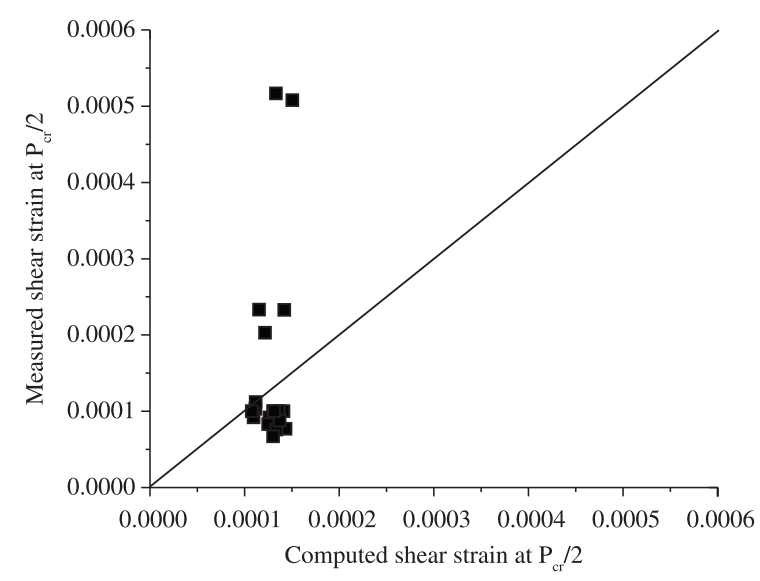

Figure 13. Comparison between computed and measured shear strains at an applied load level of $\mathrm{P}_{\mathrm{cr}} / 2$.

If the assumed stress state represents satisfactorily the experimental behavior (up to $\mathrm{P}_{\mathrm{cr}} / 2$ ), the computed strains should compare well with the experimentally determined strains (estimated based on measured load-line displacement over a gauge length of $100 \mathrm{~mm}$ ). A comparison of the computed and measured strains is made in Figure 13. The simple computations involved are presented in Appendix 1, typically for the case of a DCN specimen with $(\mathrm{a} / \mathrm{w})=0.3$ and percentage replacement equal to 50. A line of equality is also shown in Figure 13. From this figure it is noted that, except for $(\mathrm{a} / \mathrm{w})$ ratios 0.4 and 0.5 for $0 \%$ replacement ${ }^{\dagger}$, the predictions made by the assumed stress state seems to predict the observed load and load-line displacement behavior of DCN specimens up to $\mathrm{P}_{\mathrm{cr}} / 2$.

$\dagger$ which may be due to initial problems encountered in the experimental observations.
Table 1. Comparison of $\mathrm{G}_{\mathrm{IF}}$ and $\mathrm{G}_{\mathrm{IIF}}$ of crushed stone fine aggregate concrete.

\begin{tabular}{cccc}
\hline $\begin{array}{c}\text { Percentage of } \\
\text { crushed stone } \\
\text { fine aggregate } \\
\text { replacing } \\
\text { sand }\end{array}$ & $\begin{array}{c}\text { Fracture energy } \\
\text { (Mode - I) } \\
\text { fracture } \mathbf{G}_{\text {IF }} \\
\left(\mathbf{N . m}^{-1}\right)\end{array}$ & $\begin{array}{c}\text { Experimental } \\
\text { fracture energy } \\
\text { (Mode - II) } \\
\text { fracture } \mathbf{G}_{\text {IF }} \\
\left(\mathbf{N . m}^{-1}\right)\end{array}$ & $\mathbf{G}_{\mathrm{IIF}} / \mathbf{G}_{\mathrm{IF}}$ \\
\hline 0 & 89.33 & 1540.30 & 17.24 \\
25 & 100.57 & 2009.49 & 19.98 \\
50 & 102.12 & 2156.39 & 21.12 \\
75 & 99.63 & 1768.72 & 17.75 \\
100 & 94.01 & 1471.09 & 15.65 \\
\hline Average & & & 18.35 \\
\hline
\end{tabular}

\subsection{Fracture energy}

From the plots of fracture energy, $\mathrm{G}_{\mathrm{IIF}}$ vs. percentage replacement of crushed stone fine aggregate in place of sand (Figure 12) it is observed that, the fracture energy is maximum for $50 \%$ replacement, irrespective of $(\mathrm{a} / \mathrm{w})$ ratio. Thus, the fracture energy follows similar trend as cube compressive strength and split tensile strength.

Based on the available test results on Mode - I fracture of concrete, Bazant and Giraudon ${ }^{20}$ have proposed an equation for the calculation of Mode - I fracture energy of concrete (Equation 12 of Bazant et al. ${ }^{20}$ ). Though they have not considered crushed stone fine aggregate concrete, for the sake of comparison the Mode - I fracture energy $\left(\mathrm{G}_{\mathrm{IF}}\right)$ of the concretes considered in the present study are also calculated for different $(\mathrm{a} / \mathrm{w})$ ratios and for a particular percentage replacement. The average $\mathrm{G}_{\mathrm{IF}}$ and $\mathrm{G}_{\mathrm{IIF}}$ for a given percentage replacement (averaged over different $\mathrm{a} / \mathrm{w}$ ratios considered) are calculated and the ratio between $\mathrm{G}_{\mathrm{IF}}$ and $\mathrm{G}_{\mathrm{IIF}}$ are shown in Table 1. The average value of the ratio between $\mathrm{G}_{\mathrm{IIF}}$ and $\mathrm{G}_{\mathrm{IF}}$ is obtained as 18.35. The increased fracture energy in Mode II could be due to extensive aggregate interlock forces that are not present in Mode - I fracture (Swartz et al. ${ }^{21}$ ). This value of the ratio is less than the average value suggested by Bazant and Giraudon ${ }^{20}$ for normal concrete (which is 24). However, it may be noted that the authors ${ }^{20}$ have obtained a COV of 0.299 for the Mode - I fracture energy indicating that there can be large variations in fracture energy.

\section{Summary and Conclusions}

The compressive strength and split tensile strength of concrete with crushed stone fine aggregate increases up to $50 \%$ replacement and then gradually decreases. However, these strengths at even at $100 \%$ replacement are higher than those at $0 \%$ replacement, which indicates that crushed stone fine aggregate (well graded) can be utilized as a suitable alternative material for natural river sand in concrete. In the experimental investigation the effects of variations in percentage replacement and $(\mathrm{a} / \mathrm{w})$ ratio on $\mathrm{G}_{\mathrm{IIF}}$ variation are studied. The fracture energy, for a given $(\mathrm{a} / \mathrm{w})$ ratio, is found to increase with the percentage replacement up to $50 \%$ and then gradually decreases. The inclined crack patterns observed in some of the specimens could be due to random inhomogenities in concrete causing heterogeneous 
stress field distribution ahead of notch tips, the application of shear force over wide area and due to the frictional force generated between loading platens and the specimen. The

\section{References}

1. Glavind M and Petersen CM. Green concrete in Denmark. Structural concrete. 2000; 1(1):1-6. http://dx.doi.org/10.1680/ stco.2000.1.1.19

2. Celik T and Marar K. Effect of crushed stone dust on some properties of concrete. Cement and Concrete Research. 1996; 26(7):1121-1130. http://dx.doi.org/10.1016/00088846(96)00078-6

3. Topcu IB and Ugurlu A. Effect of the use of mineral filler on the properties of concrete. Cement and Concrete Research. 2003; 33(2003):1071-1075. http://dx.doi.org/10.1016/S00088846(03)00015-2

4. Donza H, Cabrera O and Irassar EF. High - strength concrete with different fine aggregate. Cement and Concrete Research. 2002; 32(2002):1755-1761. http://dx.doi.org/10.1016/S00088846(02)00860-8

5. Ribeiro S, Ribeiro DC, Dias MBS, Garcia GCR and Santos EMB. Materials research, 2011; 14(1). http://dx.doi. org/10.1590/S1516-14392011005000004

6. Zhu WC and Tang CA. Numerical simulation on shear fracture process of concrete using mesoscopic mechanical model. Construction and Building Materials. 2002; 16(2002):453-463. http://dx.doi.org/10.1016/S0950-0618(02)00096-X

7. Lovato PS, Possan E, Molin DCCD, Masuro AB and Ribeiro JLD. Modeling of mechanical properties and durability of recycled aggregate concretes. Construction and Building Materials. 2011. http://dx.doi.org/10.1016/j. conbuildmat.2011.06.043

8. Desayi P, Raghuprasd BK and Bhaskar DV. Mode II fracture of cementitious materials- part-I: Studies on specimens of some new geometries. Journal of Structural Engineering. 1999; 26(1):11-18.

9. Bureau of Indian Standards. IS:12269-1987: Specification for 53 grade ordinary portland cement. New Delhi: Bureau of Indian Standards.

10. Bureau of Indian Standards. IS: 10262-1982: Recommended guide lines of concrete mix design. New Delhi: Bureau of Indian Standards. mean value of the ratio of $\mathrm{G}_{\mathrm{IIF}}$ to $\mathrm{G}_{\mathrm{IF}}$ (considering the mean values fracture energies of different $(\mathrm{a} / \mathrm{w})$ ratios for each percentage replacement) is found to be 18.35 .

11. Reinhardt $\mathrm{HW}$ and $\mathrm{Xu} \mathrm{S}$. A practical testing approach to determine Mode II fracture energy $\mathrm{G}_{\mathrm{IIF}}$ for concrete. International Journal of Fracture. 2000; 105:107-125. http:// dx.doi.org/10.1023/A:1007649004465

12. Ferro G. On dissipated energy density in compression for concrete. Engineering Fracture Mechanics. 2006; 73(11):1510-1530. http://dx.doi.org/10.1016/j.engfracmech.2006.01.037

13. Van Mier JGM. Strain softening of concrete under multiaxial loading conditions. [Tese]. Eindhoven: Eindhoven University of Technology; 1984.

14. Van Mier JGM. Mode II Fracture Localization in Concrete Loaded in Compression. Journal of engineering Mechanics ASCE. 2009; 135(1):1-8. http://dx.doi.org/10.1061/ (ASCE)0733-9399(2009)135:1(1)

15. Van Geel E. Behaviour of concrete in multiaxial compression. [Tese]. Eindhoven: Eindhoven University of Technology; 1998.

16. Bazant $\mathrm{ZP}$ and Pfeiffer PA. Shear fracture test of concrete. Materials and Structures. 1986; 19(110):111-121. http://dx.doi. org/10.1007/BF02481755

17. Bolotin VV. Statistical methods in structural mechanics. San Francisco: Holden-Day, Inc.; 1969.

18. Whitmann FH, Slowik V and Alvaredo AM. Probabilistic aspects of fracture energy of concrete. Materials and Structures. 1994; 27:499-504. http://dx.doi.org/10.1007/ BF02473209

19. Sih GC. Mechanics of material damage in concrete. In: Carpinteri A and Ingraffea R. Fracture mechanics of concrete: Matieral characterization and testing. The Hague: Martinus Nijhoff; 1984. http://dx.doi.org/10.1007/978-94-009-6149-4_1

20. Bazant ZP and Becq-Giraudon E. Statistical prediction of fracture parameters of concrete and implications for choice of testing standard. Cement and Concrete Research. 2002; 32:592-556. http://dx.doi.org/10.1016/S0008-8846(01)00723-2

21. Swartz SE, Lu LW, Tang LD and Refai TME. Mode II Fracture Parameters Estimation for Concrete from Beam Specimens. Experimental Mechanics. 1988; 28(2):146-153. http://dx.doi. org/10.1007/BF02317565

Appendix 1. Comparision of measured and computed strains at $\mathrm{P}_{\mathrm{rr}} / 2$.

Sample calculations for the case of $50 \%$ replacement of sand with crushed stone fine aggregate and $(\mathrm{a} / \mathrm{w})=0.3$

Load at $\mathrm{P}_{\mathrm{cr}} / 2=41.16 \mathrm{kN}$

Shear resisting area of ligaments $=31500 \mathrm{~mm}^{2}$

Corresponding shear stress at $\mathrm{P}_{\mathrm{cr}} / 2=1.3067 \mathrm{MPa}$

For $50 \%$ replacement, corresponding cube compressive strength, $\mathrm{f}_{\mathrm{cu}}=35.85 \mathrm{MPa}$

For $50 \%$ replacement, corresponding cylinder compressive strength $=f_{c}^{\prime}=\left(0.8 f_{c u}\right)=28.68 \mathrm{MPa}$

For 50\% replacement, corresponding Young's modulus, $\mathrm{E}=5015\left(0.8 \mathrm{f}_{\mathrm{cu}}\right)^{0.5}=26857.19 \mathrm{MPa}$

Considering poisons ratio of concrete, $v=0.15$

Shear modulus, $\mathrm{G}=\mathrm{E} /(2(1+v))=11677.04 \mathrm{MPa}$

Computed shear strain at $P_{c r} / 2=1.3067 / 11677.04=1.119 \times 10^{-4}$

The displacement at $\mathrm{P}_{\mathrm{cr}} / 2$ in the experiment over a gauge length of $100 \mathrm{~mm}=0.0112 \mathrm{~mm}$

Experimental shear strain at $P_{c r} / 2=0.0112 / 100=1.12 \times 10^{-4}$ 